\title{
Protest Camps and Repertoires of Contention
}

From the streets of Hong Kong, to Tahrir Square, from Occupy camps to Turkey's Gezi Park, 'protest camping' has become a prominent feature of the post-2010 cycle of social movements. As a recurrent set of transnationally deployed tactics and practices, protest camping undoubtedly forms part of the contemporary repertoire of contention. Yet, while such camp occupations have increasingly gripped the public imagination, the phenomenon of protest camping is not new. There is a palpable danger of equating increased visibility with tactical novelty. Undoubtedly, the highly mediated Egyptian mobilisations in Tahrir Square in early 2011 along with the global Occupy mobilisations and Indignados occupations propelled the notion of the "protest camp" into the common lexicon. But while the idea of the "protest camp" may be new to some, the practice and performance of creating protest camps has a rich history which has evolved through multiple movements, from Anti-Apartheid to Anti-war. However, until recently, the history of the protest camp as part of the repertoire of social movements and as a site for the evolution of a social movement's repertoire has largely been confined to the histories of individual movements. Consequently, connections between movements, between camps and the significance of the protest camp itself have been overlooked.

In this research note we argue for the importance of studying protest camps in relation to social movements and the evolution of repertoires. Protest camps adapt infrastructures and practices from tent cities, festival cultures, squatting communities and land-based autonomous movements. But protest camps are not simply repertoires on their own. They also form spaces in which a variety of repertoires of contention are developed, tried and tested, diffused or sometimes dismissed. We thus argue that more attention should be given to the unique dynamics of protest camps, along with other place-based sites of ongoing protest and social reproduction, as they form key sites for the development and exchange of repertoires.

This intervention draws attention to the importance of place-based sites of ongoing protest and social reproduction for social movements (protest camps, squats, non-stop pickets, occupations, convergence centres). Such place-based sites are central to the transmission and adaptation of tactical repertoires. Place-based protest 
sites, like protest camps, provide insight into the dynamics of both successful deployments of historical tactics (i.e. Greenham women's resurrection of suffragette dress, slogans, colours and nascent chain 'lock-ons'), as well as ineffective reproductions of tactics as the result of changing contexts. For example, the US antiroads movement attempted to dig tunnels under houses marked for eviction in a practice borrowed from the Brits even though the ground soil could not support them (Laware 2002). Or, as an often discussed example, Occupiers' reliance on the 'people's mic' in Occupy camps which allowed amplified sound, even though the practice was invented to circumvent this ban (Feigenbaum, Frenzel and McCurdy 2013).

Building on the dual nature of the protest camp as part of contemporary movement's repertoire of contention and as a space of diverse repertoires, we begin by defining the concept of repertoires and of protest camps. Next, we outline the protest camp as an established component of the repertoire of contemporary movements. We organise this discussion following four interrelated infrastructures (media \& communication infrastructures; action infrastructures; governance infrastructures; recreation) that enable us to map and study the myriad of practices which comprise and sustain a protest camp using examples across a range of camps. Offering the space, time, architectures and objects for protesters to build relationships, craft actions, skillshare and host teach-ins, these place-based sites become hubs in the broader networked communication of social movements.

\section{Theorising Repertoires and Protest Camps}

The concept of repertoires of contention was first put forward by Charles Tilly (1978) and subsequently developed in his later work (e.g. Tilly 1979, 2003, 2004, 2005, 2008), can be understood as the collection of strategies and tactics a given contextually-rooted social movement both knows how to do, and chooses to deploy at a moment in time. Inevitably, the synchronic study of repertoires renders them static. Yet, in the life of movement, repertoires may evolve over time and are subject to innovation and thus academics must also be sensitive to their diachronic attributes and contexts (Tilly 2008). The concept of repertoires of contention has been picked up by other 
scholars with research examining the tactics and strategies of specific movements in the United Kingdom (Crossley 2002; Tilly 2004, 2005), Bahrain (Lawson 2004), India (Chowdhury 2013) and Latin America (Franklin 2013) as well as theorising the rise of new forms of protest such as online direct action (Costanza Chock 2003; Rolfe 2005), cyber-protest (Van Laer and Van Aelst 2009) and repertoire shifts brought on by the digitalisation of communication (della Porta 2013). Protest camps have largely been absent from this literature...

A protest camp is a place-based social movement strategy that involves both acts of ongoing protest and acts of social reproduction needed to sustain daily life (Feigenbaum, Frenzel and McCurdy 2013). Our definition allows for both social movements and campaigns that explicitly articulated a strategy or practice of 'protest camping' as well as place-based social movement actions which were labelled as 'protest camps' by mainstream media or movement discourses, even if they did not, at the time, articulate their practices in these words.

Reviewing the work of Tilly, Crossley (2002) comments on the importance of acknowledging the "social dynamics" of a repertoire as tied to a specific movement or mobilization even if it has a large general uptake. Protest camps must be viewed in a similar vein as they arise out of, and in relation to, specific cultures, movements and struggles. To see protest camps as repertoires - then - is to point to how common logics and features like the act of camping and occupying places, or the provision of care (broadly as social reproduction) and the facilitation of action are adapted in specific contexts. These specific contexts can be explored through a focus on the distinct, yet repeated infrastructures (and related practices) that comprise the life of a protest camp.

For a protest camp to emerge there needs to be a place where a camp can be erected, time for a camp to be built and become operational, and materials (tents, kitchen utensils, toilets) to make the camp function. As with repertoires, each protest camp is manifested in relation to distinct features of their place (i.e. national location, rural/urban, cement or grass, dry heat or wet snow, beside a beach or beside a cathedral); temporality (how long they last, how frequently they are evicted, what kinds of police violence and harassment they face, what the flow of campers and visitors through them are); architectures and available objects (i.e. large marquees or 
abandoned barns, bbqs or food vendors, electricity generators or nearby cafes providing power). The way that both the camp evolves as a repertoire and that it becomes a place for the adaptation, experimentation and development of repertoires are entangled in these different aspects of each encampment. Underwriting the dual perspective of protest camps as repertoires together is an emphasis on the importance of physical space and, as such, we aim to contribute to a growing literature on the importance of space and place to contentious politics (see: Martin and Miller 2003).

The study of protest camps, through the lens of their infrastructures and practices, shows that there is a potentially much broader remit of the concept of repertoires. It highlights the importance of place, temporality, architectures and objects in understanding how repertoires travel and evolve. Because protest camps are places where more specific repertoires (actions, decisions making procedures etc.) are formed and invented tested, and modified, they often become sites from which repertoires are diffused through movements and across national borders via interpersonal exchange and mediated communication. In the next section we look first at the protest camp itself as a repertoire and then turn to look at the dual aspect of the protest camp as a place for the production and reproduction of repertoires. We argue that this dual nature of protest camps and place-based protest sites more broadly, necessitates a refined understanding of repertoires. We share McAdam, Tarrow and Tilly's (2001) view of repertoires as innovative and evolving and equally stress the importance of recognising how they are premeditated by available architectures and objects, by place and temporality.

\section{The Protest Camp As A Repertoire}

Protest camping, as a repertoire, has travelled across history, movements and national contexts. The connections between different camps did not start in 2011 with the occupation of Tahrir Square inspiring M15 and Occupy. Acts of camping and creating place-based sites of social reproduction and resistance can be found throughout history, with the Diggers often cited as a proto-form of today's tent encampments. Protest camps became increasingly popular with the wave of 'New Social Movements. In 1969, inspired by the Bonus Army encampment of the early 
1930s, Resurrection City was born. Many anti-apartheid solidarity protests in the 1970s and 1980s built shantytown encampments in efforts to draw attention to the inhumane and unjust conditions of South African Apartheid. Also in the 1970s a new tactic of nuclear site occupations travelled from protest movements in the Rhine Valley to US anti-nuclear activists. In the 1980s the idea of peace camps travelled from Greenham Common to several places around the world. In the 1990s European no border camps inspired the formation of large anti summit protests in camps and in the last decade these inspired the formation of climate camps, first in the UK and then across the world. There are more lineages, pointing to the establishment of protest camp as a repertoire of protest action in the last 40 years.

Of course not all movements use protest camps and the act of protest camping may be used in different ways. Yet post-2010 across a wide range of movements we do find that there are aspects of protest camps that travel, but others that do not. Thus, of interest to social movement scholars are mapping and understanding the connections - physical and mediated - across and between protest camps. What aspects of the protest camp have been inherited from past movements? What aspects have been innovated? How has the knowledge, experience and innovation pertaining to a protest camps been diffused across space and time? While social movement scholars have used this line of questioning to study social movements more broadly, it is equally important to make these connections across protest camps. Moreover, as we argue in the next section, protest camps are more than a tactic of contemporary movements. They must also be recognised as sites where movement repertoires are made, diffused, and modified.

\section{The Protest Camp as a place for repertoire making and modelling}

Protest camps are sites where people and ideas converge. They inherit successful repertoires and histories of practice, yet are also incubators of change and innovation for a movement's repertoire. As such, studying protest camps can offer social movement scholars a better understanding of how a movement's repertoire forms and becomes modified, as well shed light on the richness of practice found at protest camps. The study of protest camps requires an approach to the production and 
reproduction of repertoires through the entanglements of place, temporality and material architectures and objects. This approach must also understand the roles played by protest camps (and related place-based protests) in the travel of repertoires-as both knowledge and tactics are bound up with physical objects. For example, successful general assembly meetings are reproduced as a repertoire through both the travel of decision-making practices (i.e. consensus, spokescouncils), as well as through the materials that support them (i.e. waterproof marquees - especially in rainy climates!).

To facilitate the study protest camps as assemblages of repertoires shaped by place, temporality and material architectures and objects, we suggest a theory and practice of 'infrastructural analysis'. We use the term 'infrastructure' to refer to the organised services and facilities protest campers build for daily living. These structures, along with the practices attached to them, function together, to allow campers to disseminate information, distribute goods and provide services (such as nonviolence training, medical care and legal support). We differentiate between four protest camp infrastructures:

- Media \& communication infrastructures and practices (media strategies, distribution networks, production techniques);

- Action infrastructures and practices (direct action tactics, police negotiations, legal aid, medical support, transportation networks);

- Governance infrastructures and practices (formal and informal decision-making processes); and

- Re-creation infrastructures and practices (food supply, shelter, sanitation, maintenance of communal and private space).

Thinking about these structures and operations as infrastructures provides a conceptual lens to disentangle, map and make sense of the ways in which protest campers develop and employ their repertoire of practices that negotiate (and fail to negotiate) ways of living and protesting together around and through the material objects, architectures and physical environments available to them. As these four dimensions interact, they enable and hinder each other, creating the distinct architecture of each protest camp (Frenzel, Feigenbaum and McCurdy 2013). In the next section we focus in on one of our four infrastructures, media and communications, to offer brief examples of 
how this infrastructural analysis can contribute to the study of repertoires. In particular we emphasise the need for heightened focus on place, temporality, material architectures and objects to generate better understandings of the evolution and travel of repertoires.

\section{Infrastructural Analysis: Media \& communication}

Since 2010 the rise in social media has sped up the protest cycle, turning both news media and activist media-making into 24/7 tasks. But for social media to be a successful repertoire for activists they need administrators, networks, content-and the often overlooked ingredient, electrical power. Beyond the infamous 'human microphone' of Occupy camps, most media and communications technologies depend on electricity in some form. It is the material architectures and objects like street lamps, generators and nearby cafes that make it possible for protesters to stay connected in an outdoor environment, especially during service provider blackouts like those used against protesters in Tahrir Square. Likewise, aspects of place like weather and topography also affects the ability to effectively engage communication technologies on a campsite. Blizzards and thunder storms can make working with electronic devices hazardous and challenging.

Re-situating these infrastructural features of place, temporality and materiality at the centre of our analysis can lead to new understanding of how repertoires are inherited, adapted, deployed and diffused. For example, at the Occupy camp in Anchorage, Alaska when the weather got too cold to use computers, livestreaming had to be stopped. In efforts to keep filming, occupiers created a system whereby they brought in propane heaters to keep the computer at a comfortable temperature. In New York City's Occupy Wall Street a system was developed whereby, if it looked like rain, media team members would bundle up computer equipment in tarpaulin and donated rain ponchos, placing them carefully into a large skip that was also lined with waterproofs. Around Tahrir Square, protesters utilised a practice that travelled into protest camp repertoires through favelas and squats, tapping into the wires of street lamps to re-route electricity when they ran out of charge. In each of these examples, the 
evolution of repertoire is entangled with the materiality of place, architecture and objects.

While there is of course a temporality to all these actions, in some examples the temporal dimension of protest becomes particularly clear. In relation to media and communication infrastructures, we see this in the 'media hours' employed by some protest camps. For example, as part of a co-ordinated media effort, the 2007 Climate Camp restricted the hours that mainstream media could access the protest camp site. Drawing directly from a strategy used at the HoriZone protest camp in Scotland two years earlier, media were offered guided tours of the camp located on the edge of London's Heathrow Airport but only during times set out by protestors. This media policy established by protest campers became the object of harsh criticism from journalists for inhibiting free speech and impeding their right to report on activities as they so desired. Protest campers, by trying to control the time journalists could access the site, were attempting to find a workable solution to internal political divisions over media access and the demands of journalists. While problematic, the open hour solution used at Climate Camp is part of the repertoire of media practices designed specifically for protest camps and highlights a core tension of protest camps as both a symbolic site of media interest and representation and a place to live, plan and work without media interference.

The tension between the protest camps as a representational or media space and as a home "homeplace" (hooks 1990) is fundamental to the repertoire of media practices develop and deployed at the protest camp. With social media and livestreaming in post-2010 social movements making it even more difficult to 'control' the separation of activist and media space, the evolution of such place-based repertoires are key to developing new tactics. As such, to make sense of how repertoires take shape between media-makers and their 'tools' (computers, phones, internet networks) demands an analysis that looks at the dynamics of resources and roles in relation to these other material dimensions of place, temporality, architecture and objects. An infrastructural analysis illuminates these dynamics, and with them, increases our capacity to understand the evolution and travel of repertoires in post 2010 social movements. 


\section{Conclusion}

The dual concept of repertoires we propose provides a framework to study how protest camps as a repertoire have developed over time and across movements. It also serves as a means to examine protest camps as sites for the production and reproduction of a variety of repertoires. The infrastructural analysis we have generated was designed to help social movement researchers disentangle the many repertoires observed at place-based sites of resistance like protest camps. This method of analysis allows one to comparatively study how different contexts shape the inheritance, deployment and diffusion of tactical repertoires. The four sets of infrastructures we propose are not discrete, nor are they the only way to think about how people come into operation together with the places, temporalities, material objects and architectures of a protest camp. Instead, they are meant to insist on the importance of place, temporality and materials in the ways we come to understand repertoires.

To date, literature on repertoires has remained focused on human relationships and resources at the expense of thinking about all the other environmental and architectural factors that shape strategies and tactics-from ground soil to freezing temperatures, from tarpaulins to tea. An infrastructural analysis emphasises the role these materials play in shaping the contexts of struggles through which repertoires manifest, resources are mobilised, and decisions are made. Infrastructural analysis thus offers the study of repertoires a lens through which to identify how repertoires are inherited and developed between protest camps, as well as how they are diffused from camps into broader struggles and movements. It is an effort to construct an analytic framework to better grasp the importance of place, temporality and materials in the ways repertoires evolve and travel, as well as how repertoires can become both reified and innovated. 


\section{Works Cited}

Chowdhury, A. R. (2013): 'Repertoires of Contention' in Movements Against Hydropower Projects in India, Social Movement Studies: Journal of Social, Cultural and Political Protest.

Costanza-Chock, S. (2003). Mapping the Repertoire of Electronic Contention. In A. Opel \& D. Pompper (Eds.), Representing Resistance: Media, Civil disobedience, and the global justice movement. London: Praeger.

Crossley, N. (2002). Repertoires of Contention and Tactical Diversity in the UK Psychiatric Survivors Movement: The question of appropriation, ocial Movement Studies: Journal of Social, Cultural and Political Protest, 1:1, 47-71,

della Porta, D. (2013). "Repertoires of Contention" in D. Snow, D. della Porta, B. Klandermans \& D. McAdam (Eds.) The Wiley-Blackwell Encyclopaedia of Social and Political Movements, Volume 3. Blackwell: Oxford.

Eyerman, R. and A. Jamison (1998) Music and Social Movements: Mobilizing traditions in the twentieth century. Cambridge: Cambridge University Press.

Franklin, J. C. (2013), Repertoires of Contention and Tactical Choice in Latin America, 1981-1995, in Nicole Doerr, Alice Mattoni, Simon Teune (Eds.) Advances in the Visual Analysis of Social Movements (Research in Social Movements, Conflicts and Change, Volume 35), Emerald Group Publishing Limited, pp.175-208

Frenzel, F. Feigenbaum A., and P. McCurdy (2013) 'Protest camps: an emerging field of social movement research'. Sociological Review, 62(3), pp. 457-474.

hooks, b. (1990). Yearning: Race, gender, and cultural politics. Boston, MA: South End Press. 
Lawson, F. H. (2003). "Repertoires of Contention in Contemporary Bahrain". in Q. Wiktorowicz (ed.) Islamic Activism: A Social Movement Theory Approach. Indiana University Press: Bloomington, IN, pp. 89-111.

Losure, M. (2002). Our Way or the Highway: Inside the Minnehaha Free State. U of Minnesota Press.

McAdam, D. (1996). The framing function of movement tactics: Strategic dramaturgy in the American civil rights movement. In D. McAdam \& J. D. Z. McCarthy, Mayer (Eds.), Comparative Perspectives on Social Movements: Political Opportunities, Mobilizing Structures, and Cultural Framings (pp. 338-355). Cambridge: Cambridge University Press.

McAdam, D., McCarthy, J. D., \& Zald, M. E. (1996). Introduction: Opportunities, mobilizing structures, and framing process - toward a synthetic, comparative perspective on social movements. In D. McAdam, J. D. McCarthy \& M. E. Zald (Eds.), Comparative Perspectives on Social Movements: Political opportunities, mobilizing structures, and cultural framings (pp. 1-20). New York: Cambridge University Press.

McAdam, D., Tarrow, S., \& Tilly, C. (2001). Dynamics of Contention. Cambridge: Cambridge University Press.

Meyer, D. and N. Whittier (1994) 'Social movement spillover'. Social Problems 41(2): 277-98.

Martin, D. G and Miller, B. (2003). Space and Contentious Politics [Special Issue]. Mobilization: An International Quarterly, 8(2).

Reed, T. V. (2005) The Art of Protest: Culture and activism from the civil rights 
movement to the streets of Seattle. Minneapolis, MN: University of Minnesota Press. Rolfe, B. (2005). "Building an Electronic Repertoire of Contention" Social Movement Studies, 4(1), pp. 65-74.

Tarrow, S. (1998). Power and Movement: Social Movements and Contentious Politics (Second ed.). Cambridge: Cambridge University Press.

Tilly, C. (1978). From Mobilization to Revolution. New York: McGraw-Hill.

Tilly, C. (1979). Repertoires of Contention in America and Britain, 1750-1830. In M. E. Zald \& J. D. McCarthy (Eds.), The Dynamics of Social Movements (pp. 126-155). Cambridge: Winthrope.

Tilly, C. (2003). Social Movements Enter the Twenty-first Century. Conference: Contentious Politics and the Economic Opportunity Structure: Mediterranean Perspectives.

Tilly, C. (2004). Social Movements, 1768-2004. London: Paradigm Publishers.

Tilly, C. (2005). Popular Contention in Great Britain 1758-1834. London: Paradigm.

Tilly, C. (2008).Contentious Performances. Cambridge: Cambridge University Press.

Van Laer, J. and Peter Van Aelst, P. (2009). "Cyber-Protest and Civil Society: the Internet and Action Repertoires in Social Movements" in Y. Jewkes and M. Yar (eds) Handbook of Internet Crimes. Willan Publishing: Portland, OR. 